\title{
Tratamiento digital de imágenes satelitales para la búsqueda y clasificación de cráteres en la Zona Sur de Honduras
}

\author{
Rafael Enrique Corrales Andino
}

\section{Resumen}

Esta investigación pretende contribuir en la conformación y aplicación de una metodología con técnicas de teledetección para la identificación de formaciones geomorfológicas características de cráteres; su área de estudio fue la zona sur de Honduras; utilizando como método el análisis digital de imágenes, con el satélite LandSat TM y la captura de firmas espectrales en campo, con un radiómetro ASD del rango visible al infrarrojo. En la primera fase, los resultados consistieron en recolección de materiales rocosos, firma espectral de coberturas del suelo para calibración de las imágenes. En la segunda fase del proyecto, se analizaron las firmas espectrales, encontrando que los materiales propios de los sitios propuestos como cráteres correspondían a material de origen volcánico, por lo que las formaciones encontradas corresponden a cráteres volcánicos, descartando la posibilidad de encontrar en esta zona específica un origen meteórico de los mismos. Tanto los filtros como los componentes principales generados para encontrar alteraciones hidrotermales, fueron prioritarios para determinar las zonas de cráteres y la radiometría para establecer el tipo de material presente y característico de uno u otro cráter (volcánico o meteórico).

Palabras clave: Radiometría de campo. Cráteres. Análisis digital de imágenes. Sur de Honduras.

\section{Abstract}

This research aims to contribute to the creation and implementation of a methodology with remote sensing techniques to identify geomorphological features of craters, their study area was the south of Honduras as a method using the digital image analysis with the LandSat satellite TM and spectral signature capture in the field, with an ASD radiometer visible-infrared range. In the first phase, results collection consisted of rocky material, firm land cover spectral calibration of the images. In the second phase, we 
analyzed the spectral signatures, finding that the materials from the proposed sites as craters correspond to volcanic material, so the formations correspond to volcanic craters, ruling out the possibility of finding in this area specific meteoric origin thereof. Both filters as main components generated to find hydrothermal alterations were to determine priority areas of craters and radiometry to establish the type of material present and characteristic of either Crater (volcanic or meteoric).

Keywords: Field Radiometry. Craters. Digital image analysis. Southern Honduras.

Rafael Enrique Corrales Andino (rafa504@yahoo.com). Departamento de Ciencia y Tecnologías de la Información Geográfica, Facultad de Ciencias Espaciales, Universidad Nacional Autónoma de Honduras. 


\section{INTRODUCCIÓN}

El uso de las tecnologías de la información geográfica está cambiando la forma de hacer ciencia, pasando de una forma analógica a una digital, esto sumado a las cada vez más utilizadas técnicas de percepción remota, que permite realizar análisis de sitios difíciles de acceso a través de imágenes de la Tierra, adquiridas por sensores transportados por plataformas aéreas o espaciales.

Stoner y Baumgardner (1981) y Galvão y Vitorello (1998, citado por Córdoba, 2009) establecen que la reflectancia es la relación entre la intensidad de luz reflejada por una cubierta y la intensidad de luz incidente sobre ella, se mide mediante espectrofotómetros de reflexión específicos o de amplio espectro compuestos por una fuente de luz y un prisma que descompone la fuente de luz en longitudes de onda distintas, obteniéndose un espectro continuo de reflectancia de la cubierta. Para Smith (et al, 1990) la radiación detectada puede ser considerada como una mezcla de diferentes respuestas espectrales procedentes de los distintos materiales que la componen. Agregado a ello la interacción de la capa atmosférica que se encuentra entre la posición del sensor y el objeto de su medida contribuye con la respuesta espectral mixta, pudiendo separarse o ser modelada mediante correlación entre los datos registrados por el sensor del satélite y los registrados por el sensor in situ.

Hasta el año 2007, no existían protocolos sobre metodologías específicas para la aplicación de radiometría de campo (Vásquez et al, 2007) de forma exhaustiva, para todo tipo de cubierta (naturales y/o antropogénicas), destacando que en la actualidad se calcula el número y tamaño de muestras para diferentes cubiertas, en su mayoría aplicando modelos estadísticos de correlación.

En el presente trabajo como lo que se pretende es establecer diferencias entre posibles áreas de cráteres y otros suelos, el área de estudio está sujeta a los patrones identificados previamente como potenciales cráteres. Dichos patrones fueron identificados por filtros utilizados para resaltar alineamientos y bordes así como de alteraciones hidrotermales, manifestado como todo cambio ambiental sobre las rocas, provocando una respuesta mineralógica, química y textural, en presencia de agua caliente, vapor o gas (Corrales, 2010). Este tipo de procesos ocurre a través de la transformación de fases minerales, crecimiento de nuevos minerales, disolución de minerales y/o precipitación, y reacciones de intercambio iónico entre los minerales constituyentes de una roca y el fluido caliente que circuló por la misma. Aunque la composición litológica inicial tiene una influencia en la mineralogía secundaria (hidrotermal), su efecto es menor que el debido a la permeabilidad, temperatura y composición del fluido (Maksaev V., 2003). 
Con técnicas de teledetección, aplicando ACP selectivos o dirigidos se puede cartografiar minerales relacionados con la alteración hidrotermal, tales como óxidos de hierro y minerales arcillosos, con contenidos potásicos, filíticas y propilíticas (Bragado, E., Rejas, J.G., Marchamalo M. \& Martínez, R. 2008).

En el mundo de la ciencia, investigadores como Delendatti, describen un ACP como una combinación lineal por la cual un conjunto de variables correlacionadas se transforma en un sistema de variables no correlacionadas llamadas componentes principales (CP) las cuales pueden describir en un espacio menos complejo la variabilidad total de los datos originales. Esto quiere decir que las transformaciones iniciales de los datos estarán referidas a un nuevo sistema de ejes ortogonales en el cual la varianza en la dirección del primer eje está maximizada. La varianza total de los componentes es igual a la varianza de las variables originales y los $\mathrm{CP}$ se ordenan según varianza decreciente.

Dentro del contexto geográfico, el estudio se desarrolló en el Valle de Choluteca, es un rectángulo de una superficie de 6,318.4 km2, ubicado en la siguiente coordenada de proyección UTM, en el centroide $479348.3128 \mathrm{E}$ $1668742.421 \mathrm{~N}$. El área comparte los departamentos de Choluteca (municipios de Choluteca, Marcovia, Namasigue y Santa Ana de Yusguare, El Corpus, El Triunfo, Orocuina y Liure) y una pequeña fracción de Valle (municipio de San Lorenzo). El valle es irrigado principalmente por el río Grande o Choluteca, el río Sampile, Estero Real y río Istoca.

\section{MÉTODO}

La metodología se centra en técnicas de teledetección (percepción remota) y de integración a un sistema de información geográfica, como se muestra a continuación:

1. Adquisición de imágenes satelitales: en esta actividad se adquirirán (compra o descarga gratuita de sitios especializados por internet) imágenes de diferentes sensores (según condiciones atmosféricas en las imágenes de sensores del rango VIS e IR).

2. Generación de diferentes filtros kernel de bordes (SIGMUR): en esta actividad se prepararán diferentes operaciones de matrices para destacar lineamientos y bordes (Valverde, s.f.) de posibles estructuras geológicas.

3. Aplicación de técnicas ADI: se desarrollaran análisis de componentes principales orientados a resaltar diferentes materiales minerales, que determinar alteraciones 0 anomalías en las rocas.

4. Giras de campo: esta actividad permitió la recolección de materiales 
rocosos de las zonas identificadas como cráteres para en una fase posterior sacar sus firmas espectrales.

5. Integración al SIG: los resultados obtenidos se integrarán en un SIG de uso público para su divulgación.

Dividido en dos fases, en la primera se cubrieron los primeros cuatro tópicos, llegando hasta las actividades de la gira de campo.

La reflectancia fue obtenida con el espectrómetro Field Spec Hand Held VNIR radiometer de ASD (Analytical Spectral Devices Inc., Boulder [CO], USA) de alta resolución, de $325 \mathrm{~nm}$ a $1075 \mathrm{~nm}$.

Para la obtención de la línea base, se realizaron mediciones del estándar de referencia, Spectralon 99\% (Labsphere, North Sutton NH, USA).

\section{RESULTADOS}

\section{1) Imagen satelital del área de estudio}

Esta es un segmento de la imagen completa del sensor LandSat Thematic Mapper (TM5), correspondiente a la fila 18 y columna 1851, para el año de 1990 (ver Figura 1). Esta imagen contiene siete bandas espectrales del rango del visible (azul, verde y rojo) e infrarrojos (infrarrojo cercano y medio).

Figura 1. Imagen p18r51 del sensor LandSat TM, con corrección atmosférica (derecha)

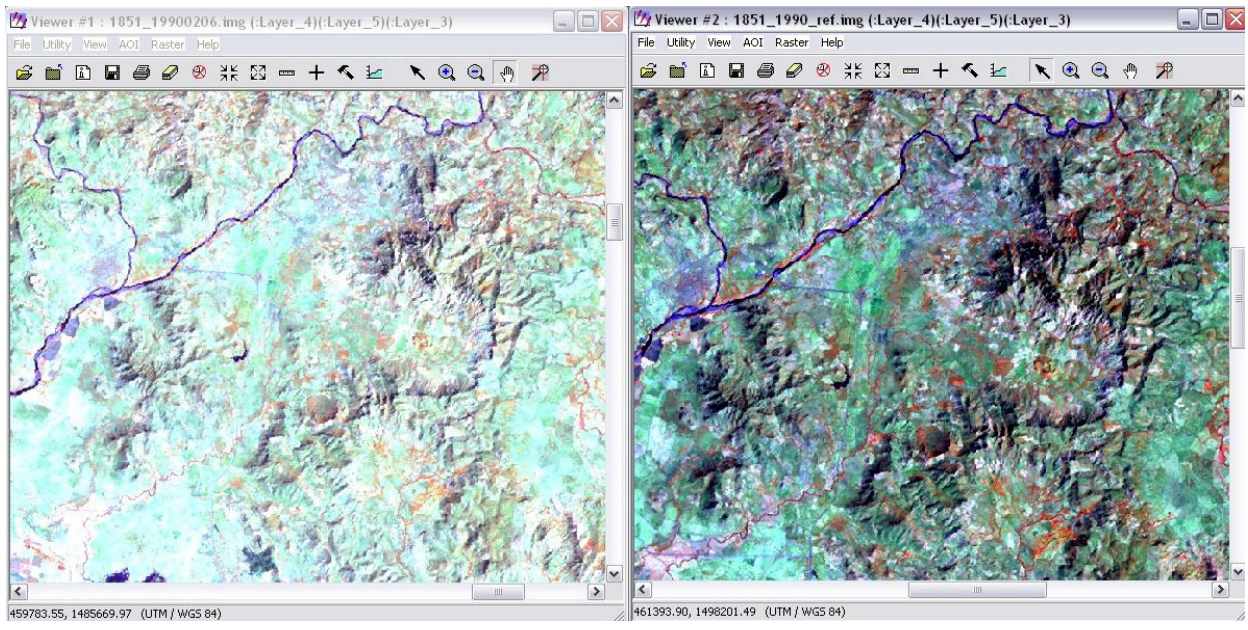




\section{2) Filtros y realces}

Los filtros aplicados a la imagen muestran una geomorfología de vestigios de más de un aparato volcánico, en lugar de impactos meteóricos (ver Figura 2), por lo que inicialmente los cráteres detectados en la imagen estarían clasificados como de origen volcánico, además la cercanía al cinturón de fuero es una base para apoyar este resultado.

Figura 2. Imagen filtrada para bordes y lineamientos, característica de cráteres

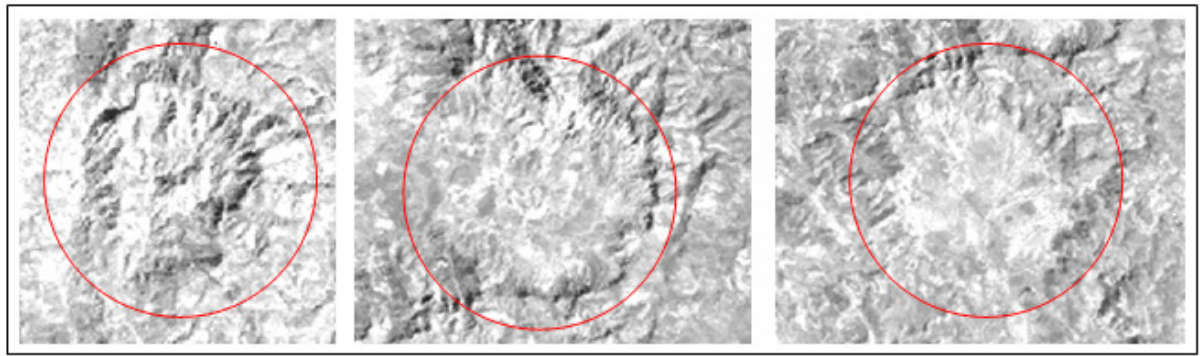

\section{3) Imagen de alteraciones hidrotermales del área de estudio en el sur de Honduras}

Se ha calculado una imagen por anomalías hidrotermales para determinar la presencia de materiales no consistentes a los patrones normales de las rocas de la capa superficial del suelo, detectándose materiales hidroxilos y óxidos de hierro, los que se pueden asociar a áreas con actividad físico química cambiantes por patrones de cambios térmicos (ver Figura 3).

Figura 3. Imagen de alteraciones hidrotermales del sur de Honduras.

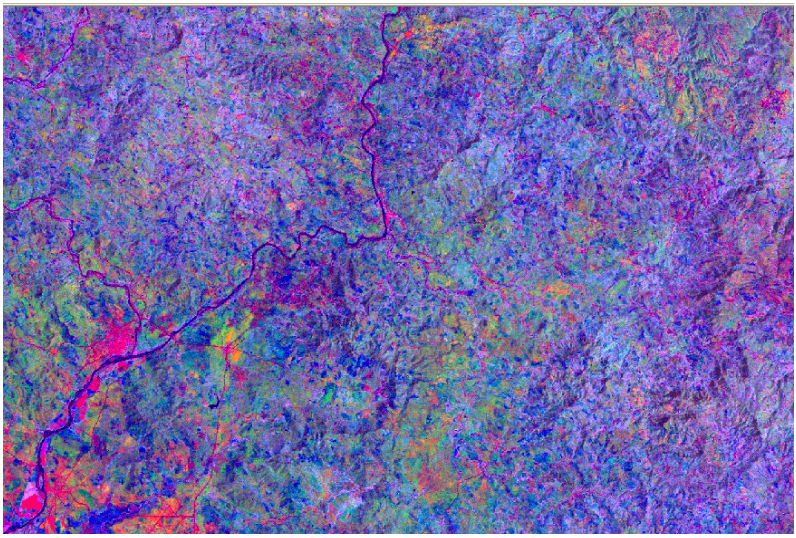




\section{4) Visita de campo}

Se llevó a cabo una gira de campo, para la identificación in situ de las diferentes formaciones geomorfológicas, así como recolección de material rocoso del área en cuestión, para ser analizadas posteriormente en el laboratorio de radiometría. Entre el equipo se encontraba el Dr. Juan Gregorio Rejas Ayuga, del Instituto Nacional de Técnica Aeroespacial, España (INTA), quien colaboró en la toma de muestras en las zonas hipotéticas de cráteres y en la toma de firmas espectrales de coberturas del suelo, para uso de calibración de la imagen (ver Figura 4). También hicimos una visita a un volcán activo como fumarola, el volcán San Cristobal en Chinandega, Nicaragua, a donde nos desplazamos para tomar muestras a diferentes alturas y estratos y correlacionarlo con las muestras de los sitios propuestos como cicatrices de cráteres en la zona sur de Honduras.

Figura 4. Registro de muestras de suelo de las cicatrices de cráter (Rafael Corrales, Juan Gregorio Rejas Ayuga y Manuel Hernandez)

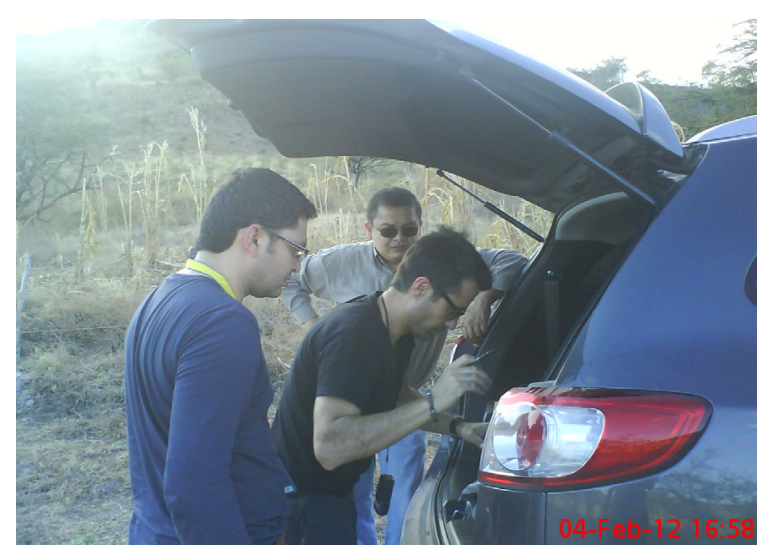

De la recolección de muestras de rocas, se identificaron por sus características físicas y visuales rocas con silicatos, unas se encontraban con exposición a altas temperaturas, asi como grava volcánica con una matriz no muy consolidada y con rastros de materia orgánica (ver Figura 5).

Entre las rocas recolectadas, las rocas provenienntes del volcán San Cristobal en Chinandega, Nicaragua (ver Figura 6) mostraban un contenido de silicatos de hierro y magnesio, grava volcánica con material orgánico y roca de arenisca con alto contenido de azufre (las que se caracterizan por su coloración amarillento). 
La radiometría de campo se centró en la medición de materiales con los que se verifica la firma espectral de coberturas de suelo desnudo y de con pastos secos por la estación del año.

La información de la radiometría de campo está basada o configurada para poder compararla con los datos extraíbles de la imagen satelital, en este caso de una imagen LandSat TM, con las siguientes características, y desplegada con el programa de tratamiento de imágenes satelitales ERDAS IMAGINE.

Figura 5

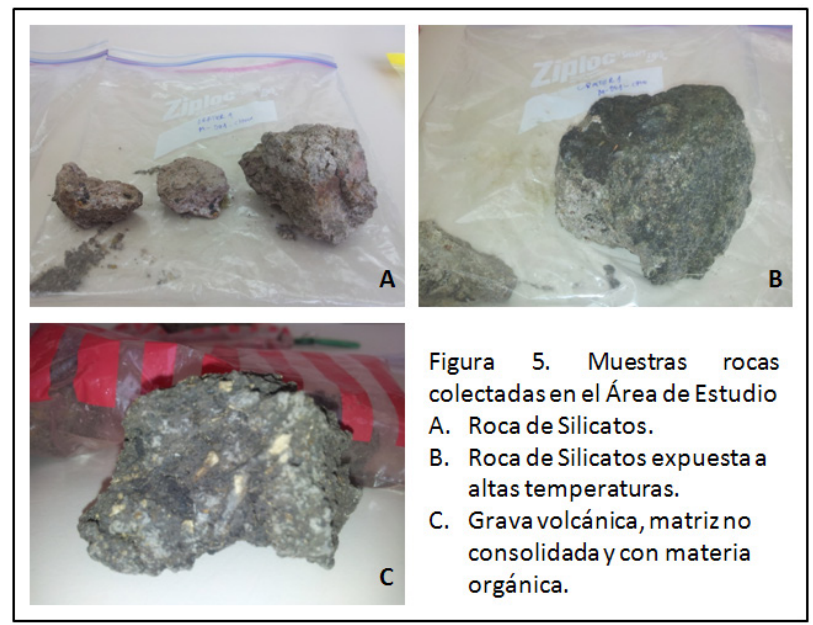

Figura 6.

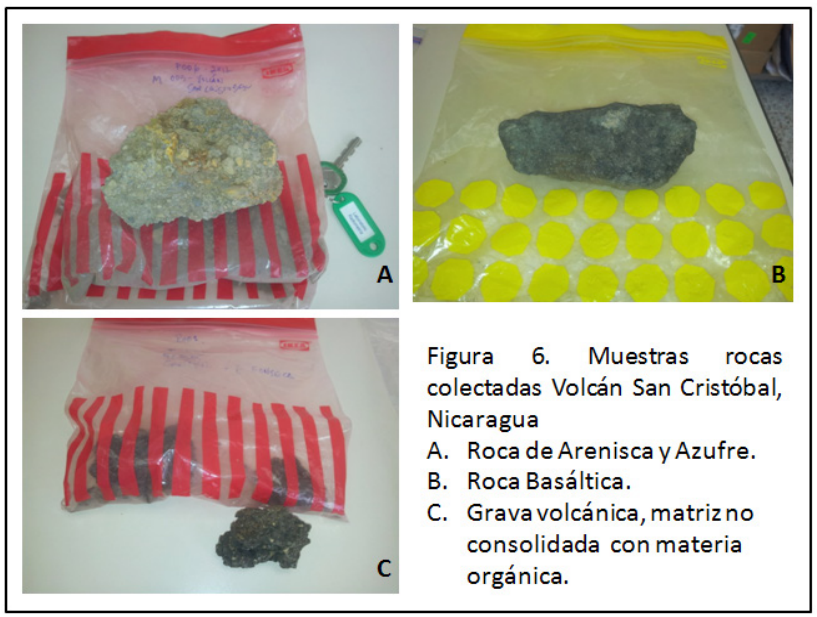




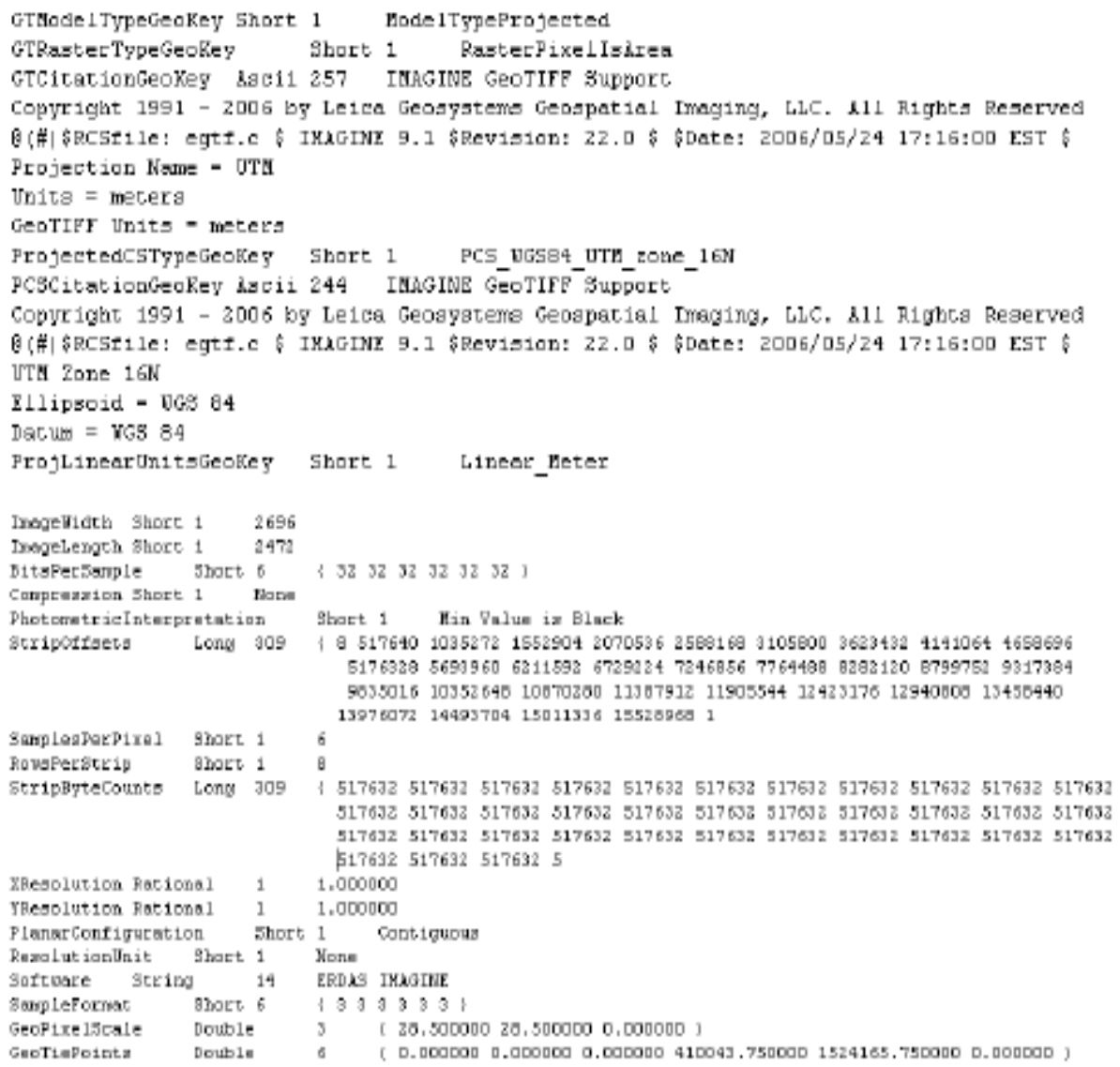

Cada imagen de este sensor contiene información en rangos de las 7 bandas espectrales, los cuales se encuentran en:

Rango visible: azul (banda 1), verde (banda 2), rojo (banda 3), infrarrojo cercano (banda 4), infrarrojo medio (banda 5), infrarrojo termal (banda 6) e infrarrojo medio (banda 7).

Como ejemplo a continuación podemos ver las gráficas de las firmas espectrales de agua, el suelo y la vegetación en la Figura 7, modificada de la ESA EDUSPACE. 
Figura 7a y 7b: Firma espectral del agua, vegetación y suelo desnudo:

A) Magnitud física en reflectancia B) Número digital, ambas por longitud de onda.
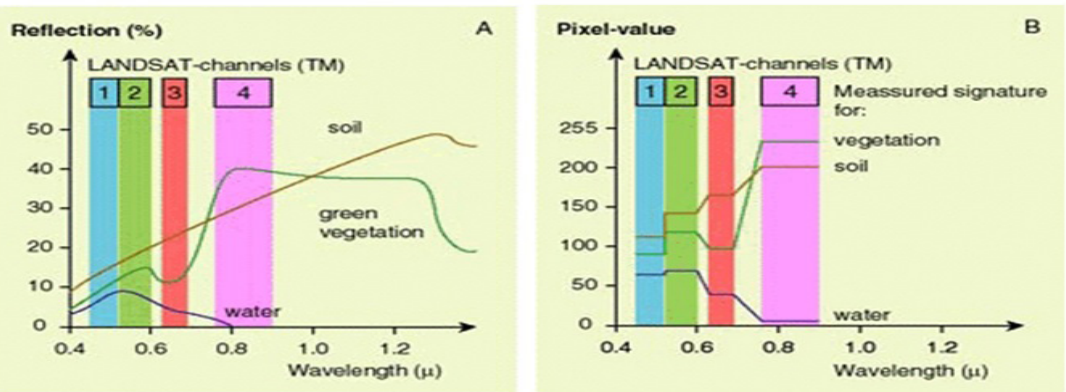

En la Figura 7a, la vegetación tiene una reflexión muy alta en el canal infrarrojo cercano 4, y una baja reflexión en el visible canal rojo 3. Esto hace que sea posible distinguir las zonas de vegetación de la tierra desnuda, o suelos rocosos. La diferencia de la reflexión en los canales 3 y 4 es ideal para áreas de vegetación e insignificante para el suelo desnudo.

En la Figura 7b, las firmas espectrales se procesan como valores digitales en el escáner del satélite. Es un ejemplo hipotético de cómo el satélite LandSat puede registrar agua, vegetación y suelo desnudo.

Los datos de campo con el espectroradiometro ASD UV/VIS/NEARIR. Los datos de campo son correlativos a datos de laboratorio o patrones estandarizados para imágenes del sensor LandSat, por lo que se mejoran los resultados para las firmas espectrales de cada muestra que será procesada en laboratorio.

A continuación se presentan las graficas de la radiometria de campo que permite establecer las condiciones en las que se encuentran los diferentes materiales del suelo, fenológicas y climatológicas (ver Figura 8), en donde por un lado tenemos dos gráficas de suelo $(A, B)$ la primera de correspondiente a tsuelos o tierras blancas, y la segunda correspondiente a gravas, en la zona de Nacaome, muy cerca de uno de los cáteres identificados en la imagen por los procesos ADI; y una tercera gráfica con vegetación típica de la zona, correspondiente a pastos en condiciones secas.

De los suelos y gravas, se observó la curva tica, baja reflectancia a nivel del infrarrojo medio del espectro electromagnético, el cual corresponde a una absorción por humedad, la cual tambien guarda relación por las condiciones del 
área de estudio (altas temperaturas y muy baja humedad del suelo).

Figura 8. Firmas espectrales de suelo desnudos (A y B) y vegetaciónen seca (C), en el Sur de Honduras.
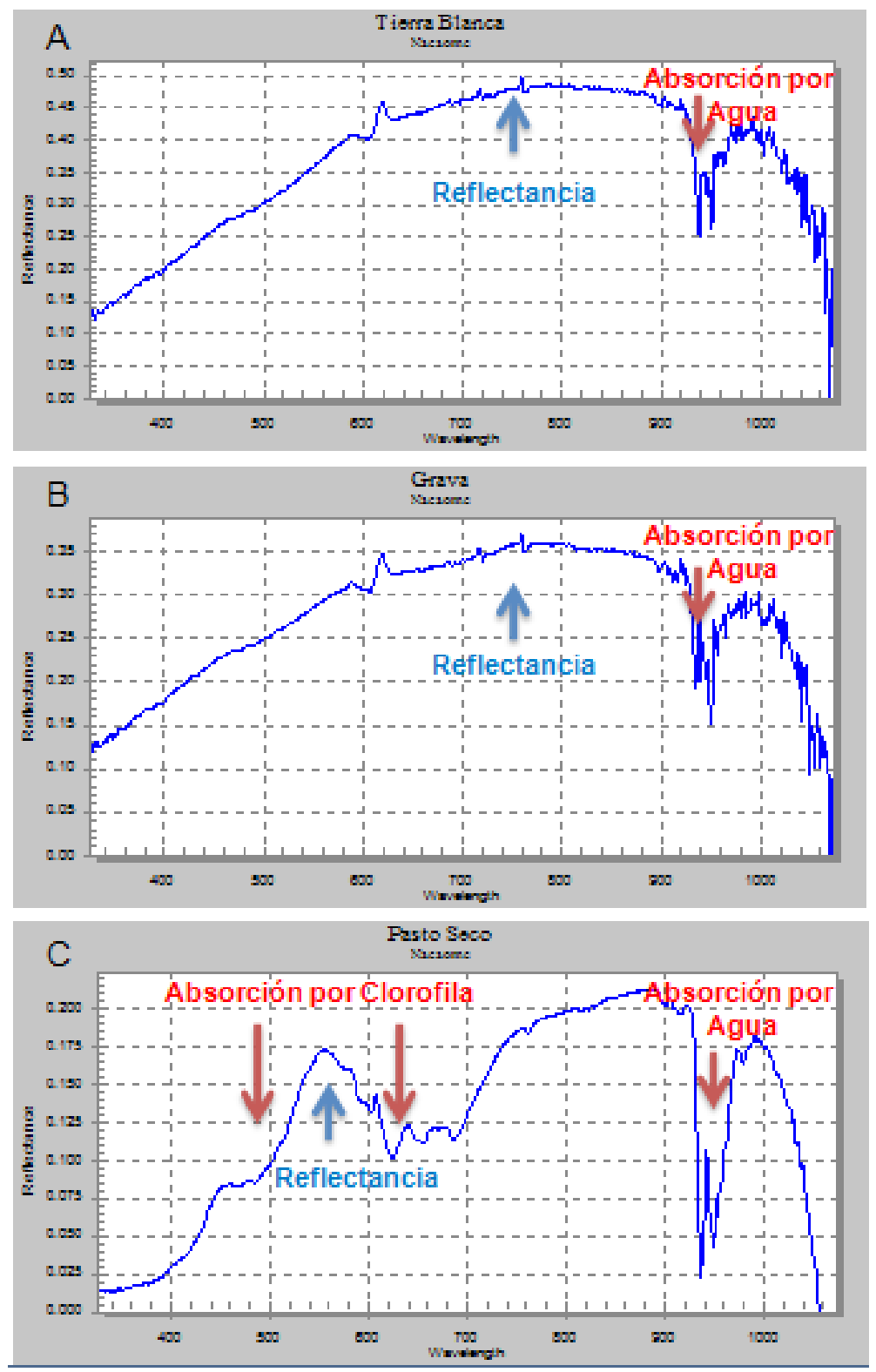
Las condiciones del área y la epoca del año en que se desarrollo la gira de campo (mes de febrero), hizo que la curva de reflectancia fuera típica para vegetación seca con un pico en el canal rojo y una disminución en el infrarojo cercano o canal cuatro, asi como una absorción de la reflectancia en el infrarojo medio mayor al encontrado en los suelos.

Los datos de campo son correlativos a datos de laboratorio o patrones estandarizados para imágenes del sensor LandSat, por lo que con esto se está logrando mejorar los resultados para las firmas espectrales de cada muestra procesada en laboratorio.

Los resultados de las muestras procesadas en laboratorio, una vez que se realizó la calibración de campo, arrojaron efectivamente una correspondencia al rango de rocas volcánicas, las tres muestras de rocas de la zona de estudio (cráter) del sur de Honduras se encuentran radiométricamente a una amplitud centrada en los mismos rangos de rocas encontradas en el volcán San Cristóbal, tal como se muestra en la Figura 9, descartando de esta manera cualquier posibilidad de ser meteóricas.

Figura 9. Firmas espectrales de los materiales rocos del volcán San Cristóbal (Nicaragua) y las muestras de la zona identificada como cráter al sur de Honduras

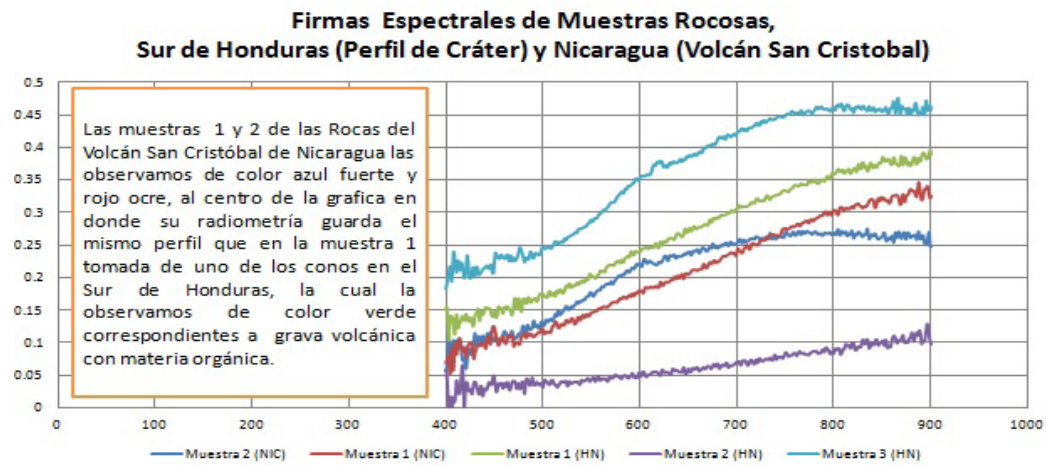

Figura 9. Firmas espectrales de los materiales rocosos del Volcán San Cristóbal (Nicaragua) y Las muestras de la zona identificada como cráter al sur de Honduras.

\section{5) Aplicación de SIG para integración de datos}

EI SIG para la administración y despliegue de información de este programa se realizara utilizando el software de uso libre: gvSIG Desktop es un Sistema de Información Geográfica(SIG), esto es, una aplicación de escritorio diseñada para capturar, almacenar, 
manipular, analizar y desplegar en todas sus formas, la información geográficamente referenciada con el fin de resolver problemas complejos de planificación y gestión. Se caracteriza por disponer de una interfaz amigable, siendo capaz de acceder a los formatos más comunes, tanto vectoriales como ráster y cuenta con un amplio número de herramientas para trabajar con información de naturaleza geográfica (herramientas de consulta, creación de mapas, geo procesamiento, redes, etc.) que lo convierten en una herramienta ideal para usuarios que trabajen con la componente territorial (Figura 10).

Figura 10. Programa SIG de uso libre, para manejar información vectorial y rasterizada (gvSIG: www.gvsig.org)

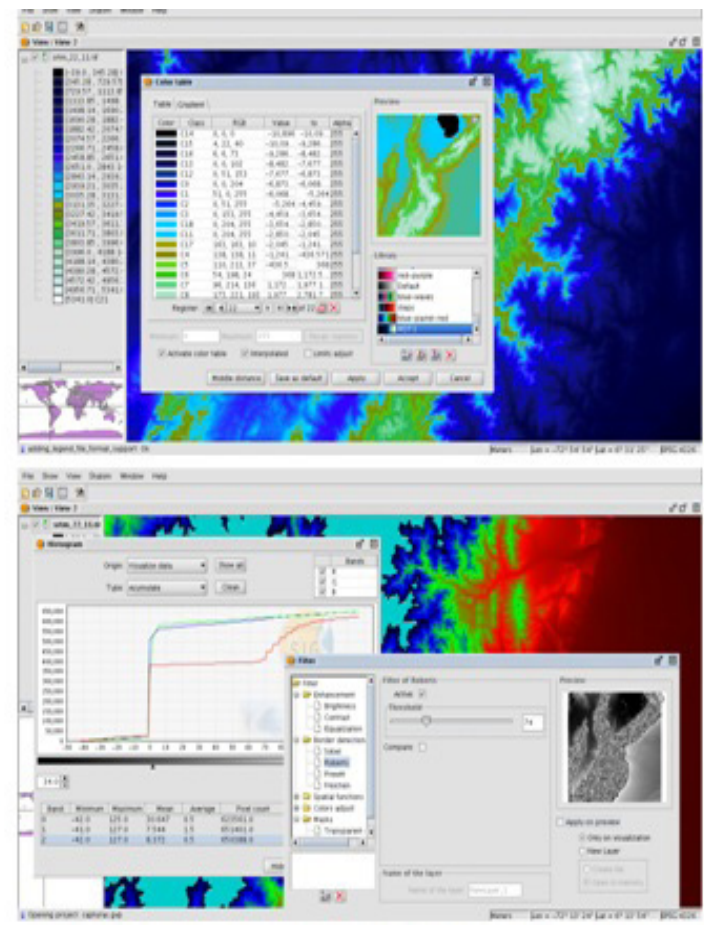

\section{DISCUSIÓN}

Por una parte, los resultados obtenidos, se encuentran dentro de los parámetros documentados por varios investigadores de las aplicaciones de técnicas de percepción remota, específicamente en el caso de la radiometría de los suelos se obtuvieron los resultados esperados en base al tipo de condiciones ambientales predominantes en el área de estudio, donde los suelos mantienen un porcentaje de humedad muy bajo (ver Figura 11), así como de las relaciones esperadas de suelos con presencia de óxidos de 
hierro, característicos de materiales con algún tipo de alteración hidrotermal, comparado con radiometría de laboratorio que muestra los patrones que debemos esperar a nivel de las diferentes bandas o canales del espectro electromagnético, tal como se muestra en la Figura 12.

Figura 11. Curvas de reflectancia del suelo por porcentaje de humedad, a) $5 \%$, b) $20 \%$ y c) $40 \%$

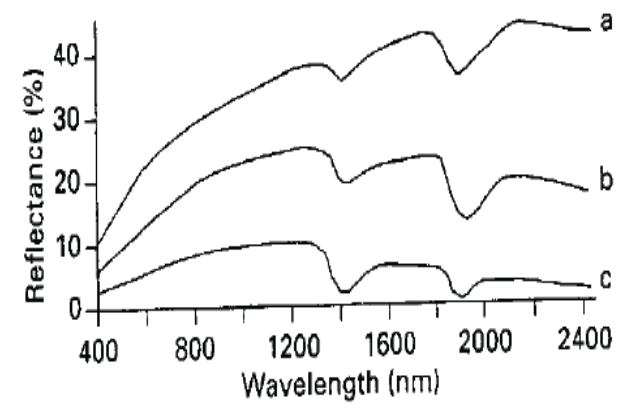

Figura 12. Curva de reflectancia de suelos francos con y sin óxidos de hierro.

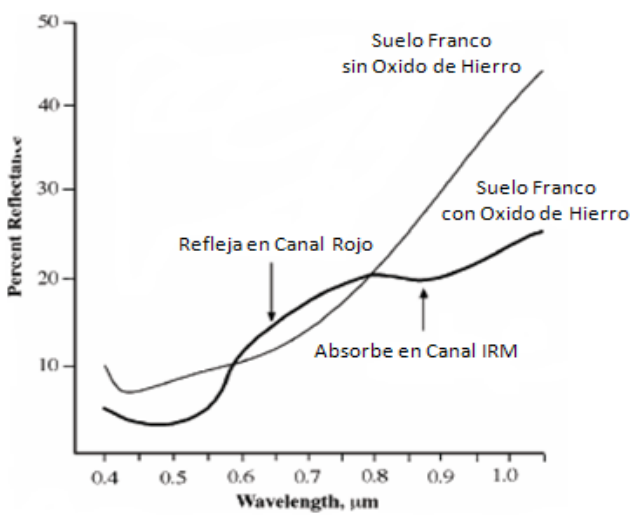

Fuente: Modificada de Jensen, 1996.

Con respecto a los resultados de la aplicación de filtros de borde en la imagen del sensor LandSat, no es suficiente para tener una base clara en la obtención de cráteres, debido que estos están muy intervenidos y se encuentran a nivel de una simple cicatriz de cráteres, por lo que fue importante, considerar las variables de alteraciones hidrotermales para contrastar identificar cráteres volcánicos o meteóricos. 


\section{CONCLUSIONES}

Al inicio se identificaron cinco áreas posibles de cráteres, de las cuales se tomo una de ellas, con el criterio de estar mas cercana al acceso vial de la zona, el material encontrado en dicho suelo rocoso se midio radiometricamente y se comparo con material del volcán San Cristobal en Chinandega, Nicaragua, con el fin de determinar origen de la formación, asi mismo las pruebas de magnetismo en el area resultaron negativas, indicando que no existia presenta de alta concentración de mineral de hierro como para relacionarlo con un crater de origen meteorico.

El uso de radiometria apoyó las observaciones de campo y tipo de materiales para esclarecer los origenes de las rocas presentes en el área.

La aplicación de filtros nos dio cinco provables áreas como formaciones de cráteres, por lo que es una tecnica que se puede seguir utilizando cuando no es evidente visualmente en las imágenes satelitales dichas formaciones.

El cruce de datos como de alteraciones hidrotermales, con la ayuda de un sistema de información geográfico vuelve mas precisa la localizacion de los cráteres, asi como evidenciar los materiales de lo que pueden estar compuestos.

En terminos generales esta metodologia se podria realizar en otras áreas del país para identificar zonas ya sea volcanicas envejecidas o posibles impactos meteoricos muy antiguos y de magnitud grande.

\section{BIBLIOGRAFÍA}

- (2008) "Measuring change in the Earth system". Proceedings of the remote sensing and photogrammetry society conference. University of Exeter.

- Bragado, E., Rejas, J.G., Marchamalo M. \& Martínez, R. (2008). Characterization of hydrothermally altered materials in the Central Volcanic Range. Costa Rica: Using TM data.

- Córdoba, P. (2009). Uso de radiometría de campo VNIR para determinar propiedades en suelos mediterráneos de zonas áridas y semiáridas. Universidad Miguel Hernández de Elche.

- Corrales R, J.G. Rejas (2010). "Caracterización de alteraciones hidrotermal y dinámica de cobertura del suelo mediante métodos de teledetección, en el Valle de Choluteca, Honduras." Tesis MOG/UNAH. 
- Delendatti, G. (2003). “Caracterización de zonas alteración hidrotermal en las imágenes del Río Castaño, provincia de San Juan, mediante procesamiento digital de imágenes TM". Revista de la Asociación Geológica de Argentina, 58 (1): pp. 97-108.

- $\quad$ ESA (ESA Eduspace) (s.f.) Disponible en: http://www.esa.int/esaMI/Eduspace ES/SEM6DYD3GXF_0.html. (Consultado en la pagina web, en mayo del 2012)

- gvSIG. Portal gvSIG (s.f.) Disponible en: http://www.gvsig.org/web/projects/ gvsig-desktop/tour/image-gallery/ (Consultado en la pagina web, en agosto del 2012):

- Jensen, J. R. (1996). Introductory Digital Image Processing: A Remote Sensing Perspective. Second Edition. Prentice Hall.

- Maksaev, V. (2003). "GL 54 A. Metalogénesis. Capítulo 8. Alteraciones hidrotermales". Facultad de Ciencias Físicas y Matemáticas, Universidad de Chile. Departamento de Geología. Disponible en: http://www.cec.uchile. $\mathrm{cl} /$ vmaksaev/metalogenesis.html.

- Smith, O, S. L. Ustin, J.B. Adams, and A. R Guillespie (1990). "A regional measure of abundance from multiespectral images. Remote Sensing Environ., Vol. 31, pp. 1-26.

- Vásquez J., A. Arquero y E. Martínez (2007). Aplicación de modelos estadísticos a la selección eficiente de cubiertas tipo mediante radiometría de campo. 